\title{
Adequacy Assessment of Integrated Nepal Power System
}

\author{
Bharat Chetry ${ }^{1}$, Navaraj Raj Karki ${ }^{2}$ \\ ${ }^{1}$ Department of Electrical and Computer Engineering, PhD Researcher of University of Porto, \\ Porto, Portugal (bharatchetry@ioe.edu.np); ${ }^{2}$ Associate Professor, Department of Electrical \\ Engineering, Pulchowk Campus, Tribhuvan University, Kathmandu, Nepal \\ (nrkarki@gmail.com)
}

\begin{abstract}
Modern electrical power systems have the responsibility of providing a reliable and economic supply of electrical energy to their customers. The economic and social effects of loss of electric service can have significant impacts on both the utility supplying electric energy and the end users of the service. Maintaining a reliable power supply is a very important issue in power system design and operation. The developing country including Nepal more often does not follow the modern planning criteria for system planning due to which we have to face problems like load shedding. This work is an exercise to detail reliability analysis of INPS using different reliability indices. The INPS has been divided into three regions and the reliability indices are found separately for each region. The two reliability indices LOLE and EENS are found to check the adequacy of generation. The load data and generation data used are all real from the only one utility of Nepal, NEA. The calculations are done according to the theory of reliability of power system on MATLAB programming. The results obtained in this work are quite satisfactory and represents the present condition of INPS.
\end{abstract}

Subject Headings. Electrical Energy, Energy Distribution, Energy Resources. Author Keywords. INPS, Integrated Nepal Power System, LOLE, Loss of Load Expectation, EENS, Expected Energy not Supplied, NEA, Nepal Electricity Authority.

\section{Introduction}

A power system serves one function only and that is to supply customers both large and small with electrical energy as economically and as reliable as possible. Modern society, because of its pattern of social and working habit, has come to expect the supply to be continuously available on demand. This is not easy physically in reality due to random system failures which are generally outside the control of power system engineers. The probability of customers being disconnected can be reduced by increased investment during either planning phase, operating phase or both. Over investment can lead to excessive operating costs which will be reflected in the tariff structure. On the other hand, underinvestment leads to the opposite situation.

A fundamental problem in system planning is the correct determination of reserve capacity. Too low value means excessive interruption while too high value results in excessive costs. The greater the uncertainty regarding the actual reliability of any installation the greater the investment wasted. The same complexity, on one side, and good engineering and sound economics, on the other, justify "the use of methods of analysis permitting the systematic evaluations of all important factors involved. There are no exact methods available which permit the solution of reserve problems with the same exactness with which, say circuit problems are solved by applying Ohm's law. However, a systematic attack of them can be made by "judicious" application of the probability theory. 
The hydropower development in Nepal began with the installation of $500 \mathrm{~kW}$ power plant at Pharping in 1911. Today Nepal is facing a severe load shedding problem due to shortage of power generation. So it seems that somewhere there is lack of proper planning. In this paper the work done to analysis the reliability of Integrated Nepal Power System is presented. It shows the reliability of the system in 2011/12. The whole INPS has been divided into three modules (areas) and the analysis is done using reliability indices. The data taken are all real from Nepal Electricity Authority (NEA).

\section{Overview of INPS}

The electricity supply system of Nepal is vertical one. There is only one organization which is under government. The power system structure of Nepal is called Integrated Nepal Power System (INPS). The annual peak demand of INPS reached 946.1 MW in F/Y 2011/2012 and the annual energy demand has reached nearly 5194.78 GWh in F/Y 2011/2012. With this increased demand the planning practices further seems incompatible as Nepal is having such severe energy crises. In this study detail analysis of planning practice has been done using reliability indices. The analysis is done for year 2011/12 due to availability of data of that time. The analysis is done by dividing the whole INPS into three geographical regions (Basin Wise).

Though the actual practice in INPS is not area-wise but it is general practice worldwide to have generation regional wise if possible. If generation is made regional wise according to the load we do not require transmission line with strong link. The requirement of capacity of transmission line will decrease a lot. Moreover the transmission line losses will also decrease. In case of Nepal we are lucky enough to have generation nearly in all regions of Nepal. So in this work the whole INPS is divided into three regions and reliability indices are found separately. Similarly the load is also added separately to each region. The three areas are: Area 1 (Kathmandu and Around), Area 2 (Eastern Region) and Area 3 (Central and Western Region).

\subsection{Area 1 (Kathmandu and around)}

Area 1 consists of generating stations nearby and around Kathmandu valley. The generating stations of Area 1 are as follows:

\begin{tabular}{clccc}
\hline S.N & Generating Stations & Capacity (MW) & FOR & Total gen. (MW) \\
\hline 1 & Chilime & $2 * 10=20$ & 0.02 & 20 \\
2 & Trisuli & $7 * 3=21$ & 0.025 & 21 \\
3 & Marsyangdi & $3 * 23=69$ & 0.03 & 69 \\
4 & Middle Marsyangdi & $2 * 35=70$ & 0.02 & 70 \\
5 & Devighat & $3 * 4.7=14.1$ & 0.02 & 14.1 \\
6 & Kulekhani-1 & $2 * 30=60$ & 0.02 & 60 \\
7 & Kulekhani-2 & $2 * 15=30$ & 0.02 & 30 \\
8 & Bhotekoshi & $2 * 22=44$ & 0.015 & 44 \\
9 & Khimti & $5 * 12=60$ & 0.02 & 60 \\
10 & Indrawati & $3 * 2.5=7.5$ & 0.03 & 7.5 \\
11 & Sunkoshi & $3 * 3.35=10.05$ & 0.02 & 10.05 \\
12 & Hetauda & $3 * 1.5$ & 0.05 & 4.5 \\
13 & Hetauda & $4 * 2.4$ & 0.05 & 9.6 \\
\hline \multicolumn{7}{l}{} & Total Generation & & $\mathbf{4 1 9 . 7 5} \mathbf{M W}$ \\
\hline
\end{tabular}

Table 1: Generation of Area 1

The above table shows that the generation of area 1 is $419.75 \mathrm{MW}$. 


\subsection{Area 2 (Eastern Region)}

The generating stations in the Eastern Part of Nepal are taken into consideration. In this combination the Multifuel Power plant of Bansbari (Duhabi) is taken into consideration. Though the power Plant of Bansbari (Duhabi) is not running at full capacity, it is considered in full capacity in this study as it is the demand of time. Moreover the generating stations in the eastern part of Nepal are very few in numbers so it is expected that the LOLE may come in higher values. The generating stations in the eastern part of Nepal are tabulated below.

\begin{tabular}{clccc}
\hline S.N & Generating Stations & Capacity (MW) & FOR & Total gen. (MW) \\
\hline 1 & Chatara & $2 * 1.6$ & 0.02 & 3.2 \\
2 & Puwa Khola & $2 * 3.1$ & 0.02 & 6.2 \\
3 & Pilwa Khola & $2 * 1.5$ & 0.015 & 3 \\
4 & Bansbari(Duhabi) & $6 * 6.5$ & 0.05 & 39 \\
5 & Katayia( Import) & $2 * 35$ & 0.03 & 70 \\
\hline \multicolumn{2}{c}{ Total Generation } & $\mathbf{1 2 1 . 4} \mathbf{~ M W}$ \\
\hline
\end{tabular}

Table 2: Generation of Area 2

As shown in above table the total generation in Area 2 is nearly $121.4 \mathrm{MW}$. The largest generation in this generation is Katayia which is actually an import from India. The diesel generation of Bansbari (Duhabi) is also taken in this combination with full capacity as it is supposed to do so in near future.

\subsection{Area 3 (Western Region) and expected load of 2015}

In this region the generating stations in the central and western part is taken into considerations. Similar to Bansbari generating stations, the Diesel Power Plant of Hetauda is also taken into consideration in full capacity. The import from India at Tanakpur is taken as generating stations with FOR of 0.02.The generation in the western part of Nepal seems to be better than eastern part of Nepal. The generating stations with generation less than 1 MW are not taken into consideration in this study. This is because of the fact that the consideration of very large no of generating stations will have many more states at capacity outage probability table which will make calculations more complicated. The generating stations of Area 3 are as tabulated as below.

\begin{tabular}{clccc}
\hline S.N & Generating Stations & Capacity (MW) & FOR & Total gen. (MW) \\
\hline 1 & Kaligandaki & $3^{*} 48$ & 0.03 & 144 \\
2 & Gandak & $3 * 5$ & 0.025 & 15 \\
3 & Jhimruk & $3^{*} 4.25$ & 0.025 & 12.75 \\
4 & Modi & $2 * 7.4$ & 0.025 & 14.8 \\
5 & Fewa & $3 * .33$ & 0.03 & 1 \\
6 & Seti & $3^{*} .5$ & 0.03 & 1.5 \\
7 & Tanakpur & $1 * 30$ & 0.02 & 30 \\
\hline & & \multicolumn{2}{c}{ Total Generation } & $\mathbf{2 1 9 . 0 5} \mathbf{~ M W}$ \\
\hline
\end{tabular}

Table 3: Generation of Area 3

The total generation in this Area is $219.05 \mathrm{MW}$. The load in the central and western part (Area 3) of INPS is found to be $240.57 \mathrm{MW}$. So it can be seen that beside Area 2, both Area1 and Area 3 have generation nearly equal to generation.

\begin{tabular}{ccc}
\hline S.N. & Area & Load (MW) \\
1 & 1 & 269.58 \\
2 & 2 & 436.17 \\
3 & 3 & 240.57 \\
\hline & Total Load & $946.1 \mathrm{MW}$ \\
\hline
\end{tabular}

Table 4: Load of all Areas 


\section{Power System Reliability Evaluation}

Considerable activity has occurred in the development and application of probabilistic techniques for power system reliability evaluation and there is a wide range of related publications. Today, most utilities have valid and applicable reliability data and most engineers have a working understanding of probability theory. The availability of highly developed reliability evaluation techniques and computer technologies has made the use of probabilistic techniques highly practical. Many utilities utilize probabilistic techniques in addition to deterministic techniques as probabilistic methods can provide quantitative input to the decision making process. Probabilistic techniques are employed extensively in system planning and operation, in both single and interconnected systems. This utilization is expected to continue to increase in the future.

For the deterministic approach, two indices are used which are reserve margin or loss of largest unit in the system, while probabilistic approaches have more indices and can provide more meaningful information to be used in design and resource planning and allocation. The commonly used probabilistic reliability indices are loss of load probability (LOLP), loss of load expectation (LOLE), loss of energy probability (LOEP), loss of energy expectation (LOEE) and expected energy not served (EENS). The Reliability indices used in power system evaluations and their categories are summarized in figure below.

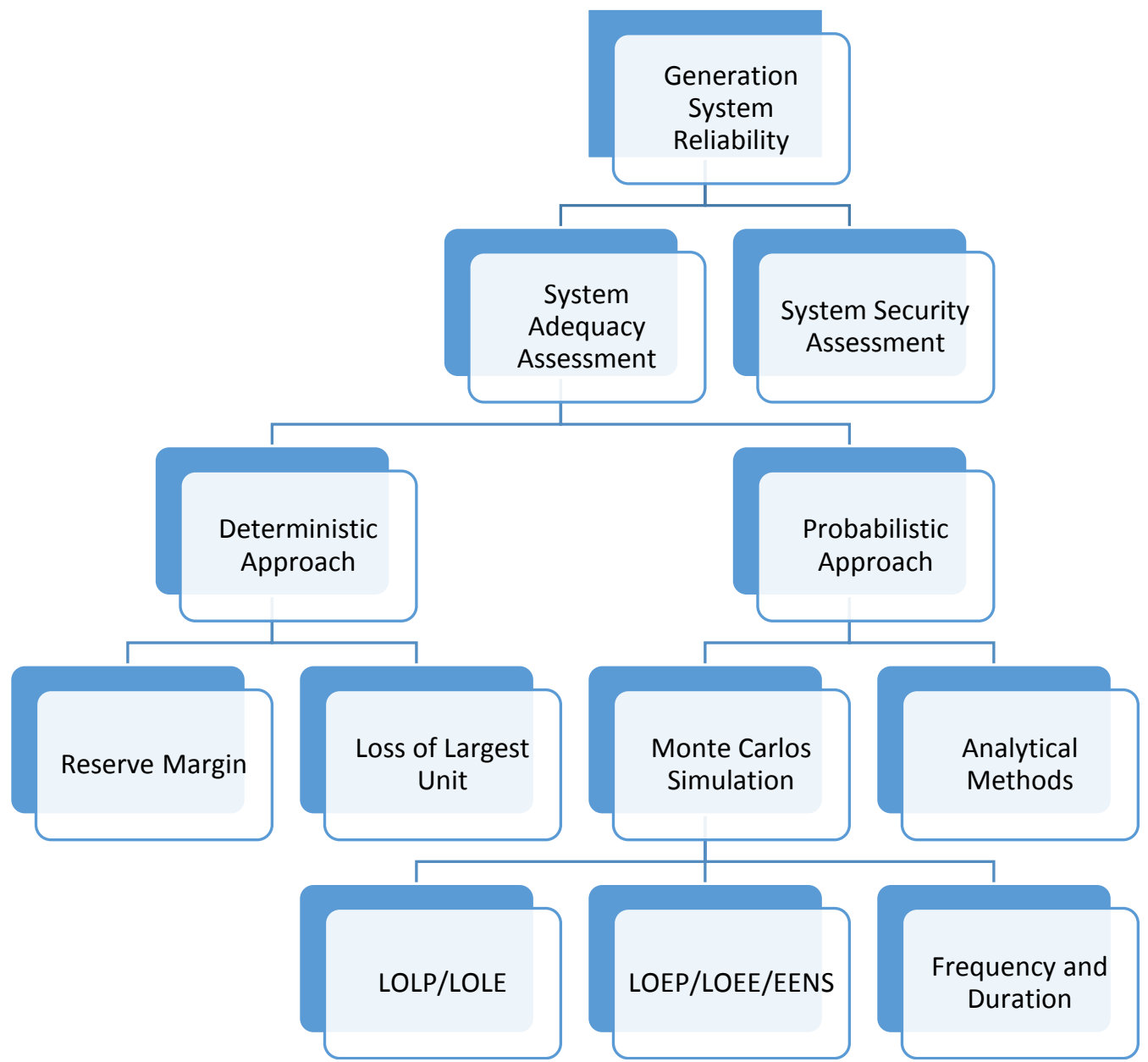

Figure 1: Generation System Reliability Assessment Indices Category

As shown in above table, among the different indices LOLE and EENS are evaluated in this paper. The deterministic analysis using just Reserve Margin calculation could lead to overinvestment in generation expansion or insufficient system reliability. Therefore, most of the utilities and system planner have been suing the probabilistic indices rather than the Reserve Margin Criteria. 


\subsection{Loss of Load and Loss of Load Expectations}

Loss of load occurs when the system load exceeds the generating capacity available for use. Loss of Load Probability (LOLP) is a projected value of how much time, in the long run, the load on a power system is expected to be greater than the capacity of the available generating resources. It is defined as the probability of the system load exceeding the available generating capacity under the assumption that the peak load of each day lasts all day.

LOLP is based on combining the probability of generation capacity states with the daily peak probability so as to assess the number of days during the year in which the generation system may be unable to meet the daily peak.

LOLP can be calculated considering the daily peak loads for 1 year duration or sometimes on each hour's load for a 24 hours day. Therefore, the same system may have two or more values of LOLP depending on how the calculation is being done.

Formula for LOLP Alternatively, a load duration curve consists of daily peak loads arranged in descending order can be used to measure LOLP for long term generation capacity evaluation. The assumption used in this case is that the peak load of the day would last all day. Capacity outages less than the amount of reserves will not contribute to loss of load. When a particular capacity outage is greater than the reserve, the risk in this case will be $p_{j} \times t_{j}$. It must be noted that an LOLE expectation index is more often used than the LOLP probability index in practical applications. The relationship between LOLE and LOLP is shown in equation 1.0 below.

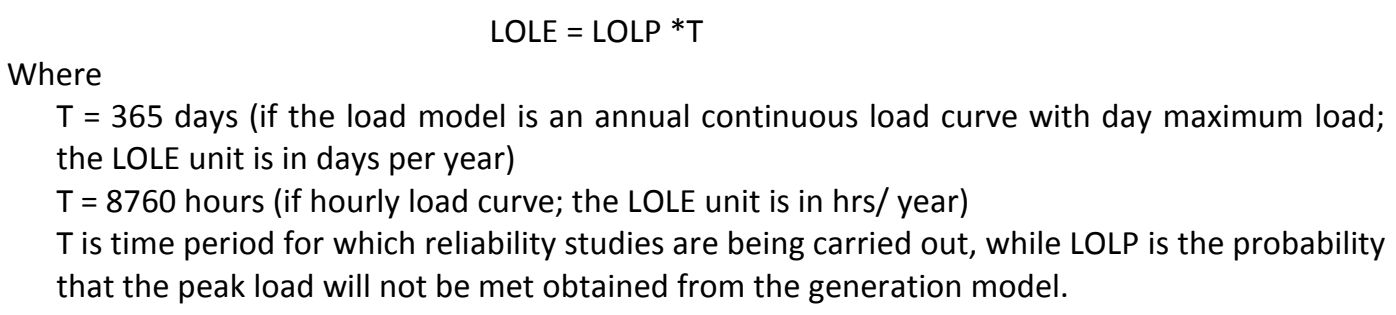

$\mathrm{T}=365$ days (if the load model is an annual continuous load curve with day maximum load; the LOLE unit is in days per year)

$T=8760$ hours (if hourly load curve; the LOLE unit is in hrs/ year)

$\mathrm{T}$ is time period for which reliability studies are being carried out, while LOLP is the probability that the peak load will not be met obtained from the generation model.

\subsection{Loss of energy}

Loss-of-energy method is another measure for generation reliability assessment. The measure of interest in this case is the ratio of the expected energy not served (EENS) during some long period of observation to the total energy demand during the same period.

A mathematical formula for the Loss of Energy Probability (LOEP) calculation is shown in equation 2 below.

Where

$$
\text { LOEP }=\frac{E_{k}}{E} \mathrm{p}_{\mathrm{k}} \mathrm{LOLE}
$$

$E k=$ The energy not supplied due to a capacity outage $O_{k}$

$\mathrm{Pk}=$ The probability of the capacity outage $O_{k}$

$\mathrm{E}=$ The total energy demand during the period of study.

The value obtained will have unit $\mathrm{MWH}$ /year and is also known as Loss of Energy Expectation (LOEE) since it is an expected value rather than a probability. Similar to the loss of load method, a load duration curve can be used to determine the LOEP for installed capacity evaluation. 


\section{Methodology}

The outline of the methodology of this study is as follows:

1. The whole INPS is divided in three zones

2. The generating capacities of generators in each zones were listed with their FOR

3. The Capacity Outage Probability of each zone was found separately as follows:

i. Input Number of units (N), FOR and capacity of units $C j$ for $j=1,2,3 \ldots$

ii. Units with identical capacities are grouped together

iii. Set $\mathrm{j}=0$, Calculate probability when no generating unit is on outage using Matlab Programming

iv. Set $\mathrm{O}=0$

v. Set $j=j+1$, Calculate probability when 1 st unit goes on outage

vi. Set $\mathrm{O}=\mathrm{O}+\mathrm{Cj}$

vii. Repeat step 5 and 6 for $j \leq N+1$, otherwise go to step 8

viii. Generate COPT for each group

ix. COPT for different groups are combined, one at a time

$x$. Final COPT for the system is then used for Adequacy assessment.

Using similar approach the COPT table of all three regions was developed. As the number of generating stations are large in numbers in Area 1 and Area 3 the COPT table was not adjusted in MATLAB so the table was written in EXCEL Sheet using 'xlswrite' command.

Adequacy Assessment evaluation method is done as below.

1. As in INPS we have large no of generators of small capacity so the number of states are very large in number of different ranges. So rounding off was done in regular intervals of $10 \mathrm{MW}$ using following formula:

$$
\begin{aligned}
& P\left(C_{j}\right)=\frac{\left(C_{k}-C_{i}\right)}{\left(C_{k}-C_{j}\right)} * P\left(C_{i}\right) \\
& P\left(C_{k}\right)=\frac{\left(C_{i}-C_{j}\right)}{\left(C_{k}-C_{j}\right)} * P\left(C_{i}\right)
\end{aligned}
$$

For all $\mathrm{i}$ states falling in the interval of $\mathrm{j}$ and $\mathrm{k}$.

2. The COPT table of two regions are combined using MATLAB programming in which inputs are Number of system, No of states, Capacity In, Capacity Out and Individual Probability. The output is written in Excel sheet.

3. Similarly the COPT table of all three regions is combined together.

4. Hourly Load Curve of INPS is plotted for one year.

5. Using combined COPT Table and Load curve the LOLE and EENS is calculated.

6. Thus evaluation is done.

\section{Reliability Evaluation Modeling}

This section describes the modeling process and Reliability indices calculation of INPS. The whole system is divided into different areas and Reliability Indices are found.

\subsection{Load Model}

In this study the hourly load of INPS are taken for fiscal year 2011/12 and load curve is plotted for 8760 hours. The peak load during this year was $946.1 \mathrm{MW}$ and the minimum load is $430 \mathrm{MW}$. Some of the data's and the curve plotted is shown in figure below. 


\begin{tabular}{ccc}
\hline S.N & HOURS & LOAD \\
\hline 1 & 1 & 946.1 \\
2 & 2 & 946.1 \\
3 & 3 & 946.1 \\
$\ldots \ldots$ & $\ldots \ldots$. & $\ldots \ldots$. \\
8758 & 8758 & 430.19 \\
8759 & 8759 & 430.01 \\
8760 & 8760 & 430 \\
\hline
\end{tabular}

Table 5: Sample of hourly load

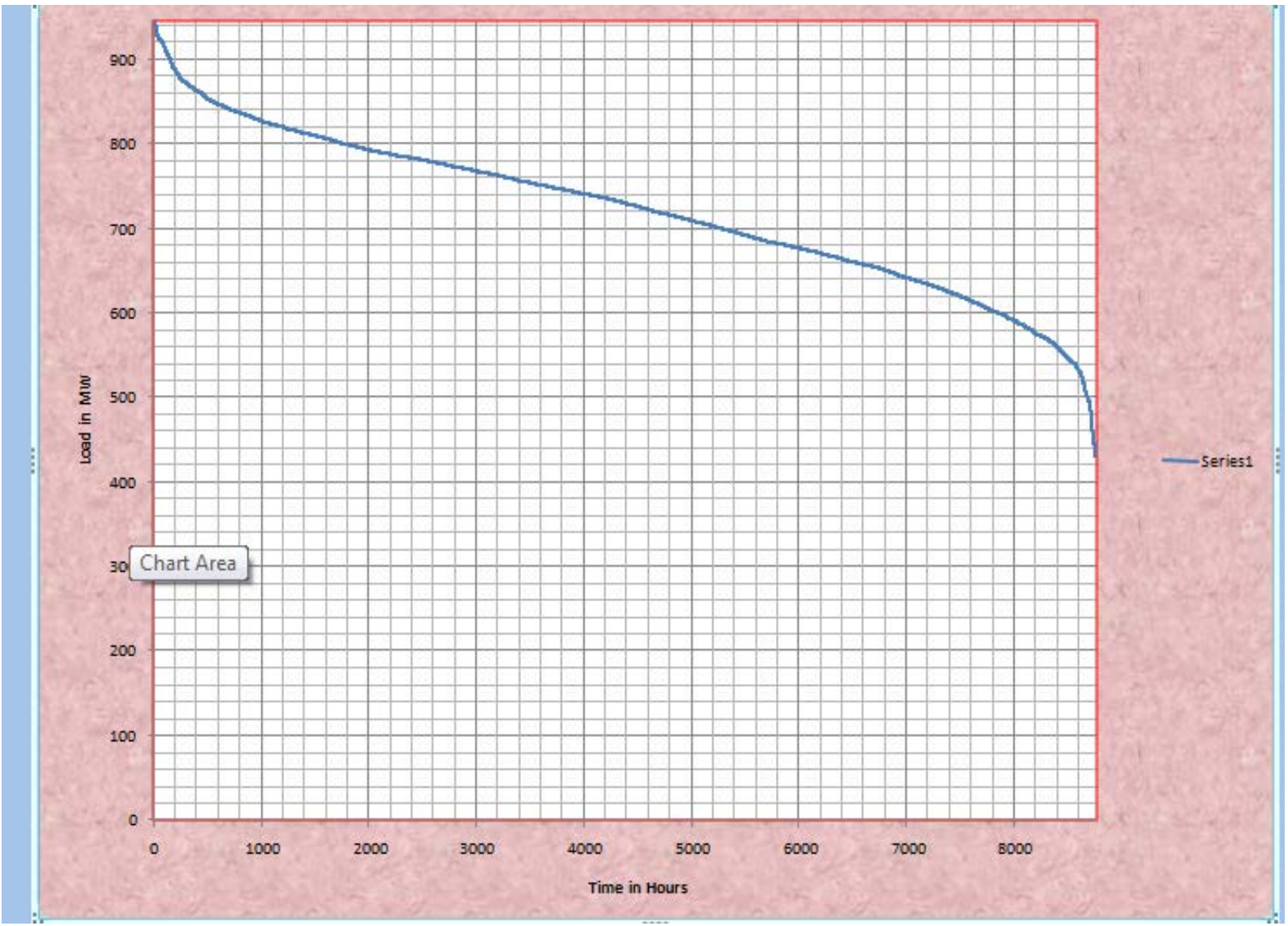

Figure 2: Hourly Load duration curve of INPS

Similar load curves are developed for each three regions and the reliability indices are found as below.

\subsection{LOLE and EENS calculation area wise}

The calculation of LOLE and EENS is shown area wise in following tables.

\begin{tabular}{ccccccc}
\hline State & Capacity Out & Capacity In & Individual Prob. & Cum. Prob. & Time of Curt. & LOLE \\
\hline 1 & 0 & 420 & 0.549620897 & 1 & 231.5418502 & 127.2602 \\
2 & 10 & 410 & 0.204581664 & 0.450379103 & 617.4449339 & 126.3179 \\
3 & 20 & 400 & 0.100024241 & 0.245797439 & 1003.348018 & 100.3591 \\
4 & 30 & 390 & 0.082024231 & 0.145773198 & 1389.251101 & 113.9523 \\
5 & 40 & 380 & 0.03956876 & 0.063748967 & 1775.154185 & 70.24065 \\
6 & 50 & 370 & 0.013233561 & 0.024180207 & 2161.057269 & 28.59848 \\
7 & 60 & 360 & 0.006980856 & 0.010946646 & 2546.960352 & 17.77996 \\
8 & 70 & 350 & 0.0026464 & 0.003965791 & 2932.863436 & 7.761531 \\
9 & 80 & 340 & 0.000840962 & 0.00131939 & 3318.76652 & 2.790958 \\
\hline
\end{tabular}




\begin{tabular}{|c|c|c|c|c|c|c|}
\hline 10 & 90 & 330 & 0.000328867 & 0.000478428 & 3704.669604 & 1.218344 \\
\hline 11 & 100 & 320 & 0.000106049 & 0.000149561 & 4090.572687 & 0.433801 \\
\hline 12 & 110 & 310 & 3.04642E-05 & 4.3512E-05 & 4476.475771 & 0.136372 \\
\hline 13 & 120 & 300 & 9.50827E-06 & $1.30478 \mathrm{E}-05$ & 4862.378855 & 0.046233 \\
\hline 14 & 130 & 290 & $2.65759 \mathrm{E}-06$ & 3.53954E-06 & 5248.281938 & 0.013948 \\
\hline 15 & 140 & 280 & $6.58625 \mathrm{E}-07$ & 8.81946E-07 & 5634.185022 & 0.003711 \\
\hline 16 & 150 & 270 & $1.7328 \mathrm{E}-07$ & $2.23321 \mathrm{E}-07$ & 6020.088106 & 0.001043 \\
\hline 17 & 160 & 260 & $3.92288 \mathrm{E}-08$ & 5.00415E-08 & 6405.991189 & 0.000251 \\
\hline 18 & 170 & 250 & 8.54938E-09 & $1.08126 \mathrm{E}-08$ & 6791.894273 & $5.81 \mathrm{E}-05$ \\
\hline 19 & 180 & 240 & $1.85137 \mathrm{E}-09$ & $2.26326 \mathrm{E}-09$ & 7177.797357 & $1.33 \mathrm{E}-05$ \\
\hline 20 & 190 & 230 & $3.35754 \mathrm{E}-10$ & 4.11895E-10 & 7563.700441 & $2.54 \mathrm{E}-06$ \\
\hline 21 & 200 & 220 & $6.37262 E-11$ & 7.61405E-11 & 7949.603524 & 5.07E-07 \\
\hline 22 & 210 & 210 & $1.04526 \mathrm{E}-11$ & $1.24143 \mathrm{E}-11$ & 8335.506608 & $8.71 \mathrm{E}-08$ \\
\hline 23 & 220 & 200 & $1.68563 \mathrm{E}-12$ & $1.96175 \mathrm{E}-12$ & 8721.409692 & $1.47 \mathrm{E}-08$ \\
\hline 24 & 230 & 190 & $2.39464 \mathrm{E}-13$ & $2.76121 \mathrm{E}-13$ & 8760 & 2.1E-09 \\
\hline 25 & 240 & 180 & 3.16164E-14 & $3.66575 \mathrm{E}-14$ & 8760 & 2.77E-10 \\
\hline ....... & $\ldots \ldots$. & $\ldots \ldots$. & ................. & …….............. & ……............ & ..................... \\
\hline 28 & 270 & 150 & 3.33127E-17 & 1.12997E-15 & 8760 & $2.92 \mathrm{E}-13$ \\
\hline 39 & 380 & 40 & $2.24282 E-36$ & $1.09376 \mathrm{E}-15$ & 8760 & $1.96 \mathrm{E}-32$ \\
\hline 40 & 390 & 30 & $1.84525 E-40$ & $1.09376 \mathrm{E}-15$ & 8760 & $1.62 \mathrm{E}-36$ \\
\hline 41 & 400 & 20 & $2.002 \mathrm{E}-45$ & $1.09376 \mathrm{E}-15$ & 8760 & $1.75 \mathrm{E}-41$ \\
\hline 42 & 410 & 10 & $2.31678 \mathrm{E}-51$ & $1.09376 \mathrm{E}-15$ & 8760 & $2.03 E-47$ \\
\hline 43 & 420 & 0 & $1.45401 \mathrm{E}-58$ & $1.09376 \mathrm{E}-15$ & 8760 & $1.27 \mathrm{E}-54$ \\
\hline & & & & \multicolumn{2}{|c|}{ LOLE of Area 1} & $.91 \mathrm{hrs} / \mathrm{yr}$ \\
\hline
\end{tabular}

Table 6: LOLE of Area 1

The above table shows the Loss of Load Expectation of area 1 which is $\mathbf{5 9 6 . 9 1} \mathbf{~ h r s / y r}$. The LOLE of whole INPS taking full capacity of generators is found to be $\mathbf{3 3 2 5} \mathbf{h r s} / \mathrm{yr}$. So if we take area wise this data is quite satisfactory.

\begin{tabular}{|c|c|c|c|c|c|c|}
\hline State & Capacity Out & Capacity In & Individual Prob. & Cumulative Prob. & $\begin{array}{l}\text { Energy } \\
\text { Curtailed }\end{array}$ & EENS \\
\hline 1 & 0 & 420 & 0.549620897 & 1 & 500 & 274.8104 \\
\hline 2 & 10 & 410 & 0.204581664 & 0.450379103 & 800 & 163.6653 \\
\hline 3 & 20 & 400 & 0.100024241 & 0.245797439 & 1750 & 175.0424 \\
\hline 4 & 30 & 390 & 0.082024231 & 0.145773198 & 4000 & 328.0969 \\
\hline 5 & 40 & 380 & 0.03956876 & 0.063748967 & 8000 & 316.5501 \\
\hline ...... & $\ldots \ldots$. & ......... & …………......... & $\ldots$ & $\ldots \ldots \ldots \ldots$ & …….............. \\
\hline 39 & 380 & 40 & $2.24282 E-36$ & $1.09376 \mathrm{E}-15$ & 2476600 & $5.55 \mathrm{E}-30$ \\
\hline 40 & 390 & 30 & $1.84525 \mathrm{E}-40$ & $1.09376 \mathrm{E}-15$ & 2564200 & $4.73 E-34$ \\
\hline 41 & 400 & 20 & $2.002 \mathrm{E}-45$ & $1.09376 \mathrm{E}-15$ & 2651800 & $5.31 E-39$ \\
\hline 42 & 410 & 10 & $2.31678 \mathrm{E}-51$ & $1.09376 \mathrm{E}-15$ & 2739400 & $6.35 \mathrm{E}-45$ \\
\hline \multirow[t]{2}{*}{43} & 420 & 0 & $1.45401 \mathrm{E}-58$ & $1.09376 \mathrm{E}-15$ & 2827000 & 4.11E-52 \\
\hline & & & & EENS of Area 1 & \multicolumn{2}{|c|}{ 1799.44 MWh/yr } \\
\hline
\end{tabular}

Table 7: EENS of Area 1 
The above table shows the expected energy not served of area 1 is $1799.44 \mathrm{MWh} /$ year. As the loss of load expectation is not very high for area 1, the EENS is also not very high.

Similarly the LOLE of area 2 and area 3 was found to be $8760 \mathrm{hrs} /$ year and $\mathbf{1 1 6 2 . 1 8} \mathrm{hrs} / \mathrm{year}$ respectively. The EENS of area 2 and area 3 was found to be $\mathbf{2 2 1 5 1 9 . 0 8} \mathbf{M W h} /$ year and $\mathbf{5 2 0 9}$ $\mathrm{MWh} /$ year respectively.

\section{Result and Discussion}

This study shows that the present scenario of INPS is not good if we analyze it from adequacy point of view. These data of LOLE and EENS are evaluated considering the generators are running at full capacity and the Diesel power plant of Hetauda and Bansbari are also running at full capacity. So the overall power system scenario seems to be very bleak as far as reliability is concerned.

So it is demand of the time to incorporate probabilistic reliability criteria as integral part of the system planning. It is also necessary to set a threshold maximum value of LOLE for INPS when carrying out system expansion planning. Accordingly the plans are also to be implemented with high priority so that the threshold value is achieved within time.

The evaluation shows that if we consider different areas separately the Area 2 (Eastern Region) is in terrible condition with LOLE of $\mathbf{8 7 6 0}$ hrs/year.Area 1 has LOLE of $\mathbf{5 9 6 . 9 1}$ hrs/year. Area 3 has LOLE of $\mathbf{1 1 6 2 . 1 8} \mathbf{~ h r s / y e a r . ~ W h e n ~ a n a l y s i s ~ i s ~ d o n e ~ a r e a ~ w i s e ~ t h e ~ s t a t u s ~ o f ~}$ area 1 is not encouraging. Area 2 has LOLE of $\mathbf{8 7 6 0 ~ h r s / y e a r ~ a n d ~ E E N S ~ o f ~} 221519.08$ $\mathrm{MWh} /$ year. The result obtained in this study is shown in graphical representation in figure 3.

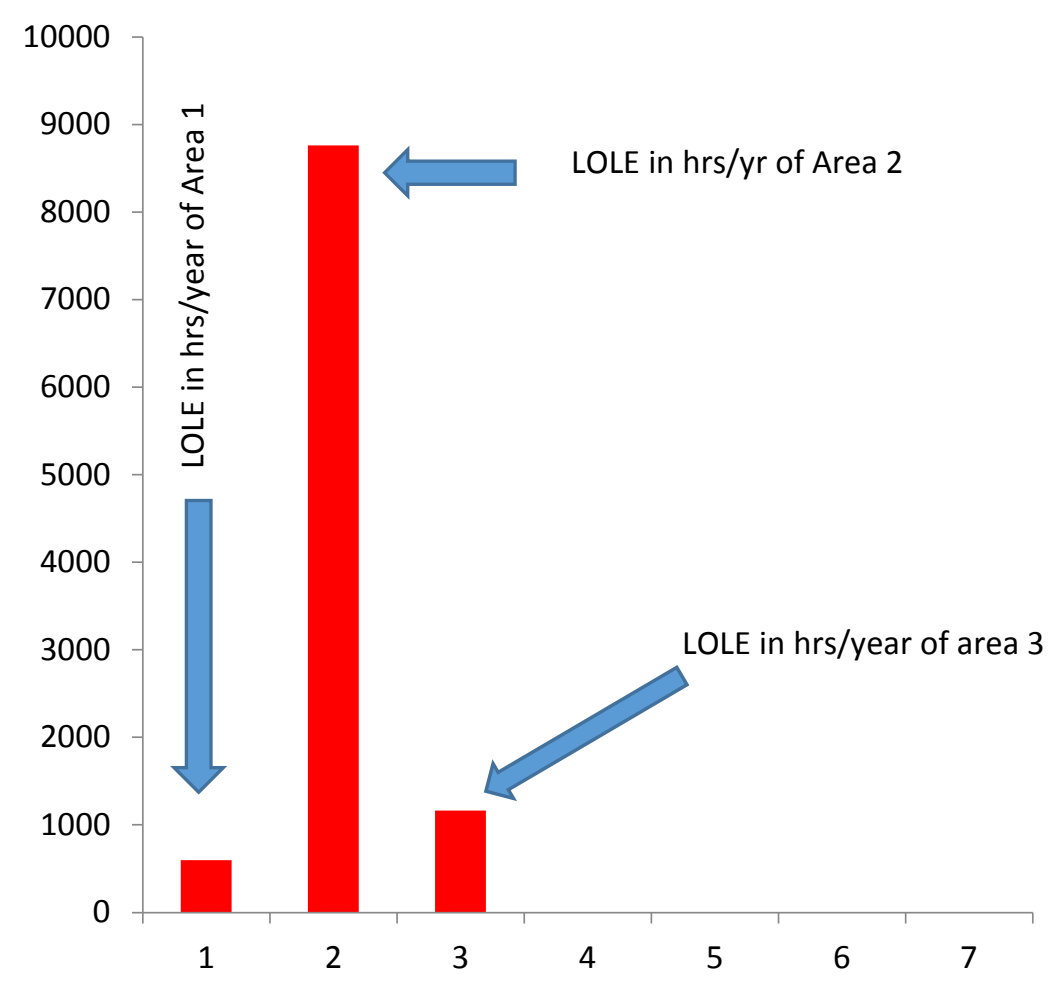

Figure 3: Graphical representation showing LOLE of different areas of INPS

\section{References}

Billinton, R., and M. Fotuhi-Firuzabad. "A Basic Framework for Generating System Operating Health Analysis." Power Systems, IEEE Transactions on 9, no. 3 (1994): 1610-17. 
Billinton, R., and Ge Jingdong. "A Comparison of Four-State Generating Unit Reliability Models for Peaking Units." Power Systems, IEEE Transactions on 19, no. 2 (2004): 763-68.

Billinton, R., and A. Jonnavithula. "Composite System Adequacy Assessment Using Sequential Monte Carlo Simulation with Variance Reduction Techniques [Power Networks]." Generation, Transmission and Distribution, IEE Proceedings- 144, no. 1 (1997): 1-6.

Billinton, R., and R. Mo. "Composite System Maintenance Coordination in a Deregulated Environment." Power Systems, IEEE Transactions on 20, no. 1 (2005): 485-92.

Billinton, R., and J. Tatla. "Composite Generation and Transmission System Adequacy Evaluation Including Protection System Failure Modes." Power Engineering Review, IEEE PER-3, no. 6 (1983): 58-58.

Billinton, R., Gao Yi, and R. Karki. "Composite System Adequacy Assessment Incorporating Large-Scale Wind Energy Conversion Systems Considering Wind Speed Correlation." Power Systems, IEEE Transactions on 24, no. 3 (2009): 1375-82.

Kumar, S., and R. Billinton. "Adequacy Evaluation of a Small Area in a Large Composite Power Network." Power Systems, IEEE Transactions on 4, no. 2 (1989): 551-58.

Kuruganty, P. R. S., P. R. Thompson, and R. Billinton. "A Reliability Assessment of the Western Canada Grid." Power Apparatus and Systems, IEEE Transactions on PAS-102, no. 9 (1983): 2826-33.

Lightfoot, L. A. "Reliability Evaluation of Engineering Systems." Electronics and Power 29, no. 11.12 (1983): 814.

Salvaderi, L., and R. Billinton. "A Comparison between Two Fundamentally Different Approaches to Composite System Reliability Evaluation." Power Apparatus and Systems, IEEE Transactions on PAS-104, no. 12 (1985): 3486-92. 